\title{
POPIS ŠTITASTIH UŠı (Hemiptera: Coccomorpha) NA DOMAĆINIIMA IZ RODA Quercus L. U HRVATSKOJ S NAGLASKOM NA PRVI NALAZ ŠTITASTE UŠI HRASTA CRNIKE - Kermes vermilio Planchon, 1864
}

\author{
CHECK LIST OF SCALE INSECTS (Hemiptera: Coccomorpha) \\ ON HOST PLANTS OF GENUS Quercus L. IN CROATIA, \\ WITH EMPHASIS ON THE FIRST RECORD OF KERMES \\ BERRY - Kermes vermilio Planchon, 1864
}

Tatjana MASTEN MILEK1, Gabrijel SELJAK², Mladen ŠIMALA², Maja PINTAR, Vjekoslav MARKOTIĆ1

\begin{abstract}
Sažetak
Popis štitastih uši na domaćinima iz roda Quercus L. sastavljen je od svih dostupnih literaturnih podataka faunističkih istraživanja štitastih uši u Hrvatskoj i podataka faunističkih istraživanja koja su trajala od 2005. do 2014. Prema literaturnim podacima u Hrvatskoj registrirano je 15 vrsta štitastih uši na hrastu. Istraživanjima je utvrđeno 12 vrsta štitastih uši, od kojih je u odnosu na vrste iz literaturnih podataka registrirano šest novih. U ovom trenutku popis štitastih uši na hrastovima obuhvaća 21 vrstu iz četiri porodice kako slijedi: porodica Asterolecanidae: Asterodiaspis ilicicola (Targioni Tozzetti 1888), A. quercicola (Bouche 1851), A. variolosa (Ratzeburg 1870), porodica Coccidae: Coccus hesperidum Linnaeus 1758, Eulecanium tiliae (Linnaeus 1758), Parthenolecanium rufulum Cockerell 1903, Pulvinaria sericea (Fourcroy 1785), porodica Diaspididae: Chionaspis etrusca Leonardi 1908, C. lepineyi Balachowsky 1928, C. salicis (Linnaeus 1758), Diaspidiotus alni (Marchal 1909), D. bavaricus (Lindinger 1912), D. ostreaeformis (Curtis 1843), D. zonatus (Frauenfeld 1868), Gonaspidiotus minimus (Leonardi in: Berlese \& Leonardi 1896), Lepidosaphes beckii (Newman 1869), L. ulmi (Linnaeus 1758), Targionia vitis (Signoret 1876) i porodica Kermesidae: Kermes quercus (Linnaeus 1758), K. roboris (Fourcroy 1785) i K. vermilio Planchon 1864.

U srpnju 2014. godine, zamijećeno je propadanje hrasta crnike u Poreču. Nakon što je obavljen vizualni pregled, uzeti su uzorci. Dijagnostička analiza, koja je obavljena u Laboratoriju za zoologiju Zavoda za zaštitu bilja, pokazala je da se radi o štitastoj uši crnike K. vermilio. Budući da je ovo prvi nalaz K. vermilio u Hrvatskoj, vrstu možemo smatrati novim članom hrvatske entomofaune. Ova štitasta uš napada zimzelene domaćine iz roda Quercus, ponaj= prije Quercus ilex L. Široko je rasprostranjena u zemljama Mediteranskog bazena. U prošlosti, štitasta uš K. vermilio imala je značajnu gospodarsku važnost kao izvor crvene boje za tkaninu, no danas ima status invazivnog gospodarski značajnog štetnika.
\end{abstract}

KLJUČNE RIJEČI: hrast, Hrvatska, Kermes vermilio, prvi nalaz, štitasta uš crnike, štitaste uši

\footnotetext{
1 Dr. sc. Tatjana Masten Milek, tatjana.masten.milek@hcphs.hr, Vjekoslav Markotić, dipl. ing., vjekoslav.markotic@hcphs.hr, Hrvatski centar za poljoprivredu, hranu i selo, Svetošimunska 25, 10000 Zagreb

${ }^{2}$ Mr. sc. Gabrijel Seljak, Kmetijsko gozdarski zavod Nova Gorica, Pri hrastu 18, Kromberk, 5000 Nova Gorica, gabrijel.seljak@go.kgzs.si

${ }^{3}$ Dr. sc. Mladen Šimala, mladen.simala@hcphs.hr, Maja Pintar, dipl. ing., maja.pintar@hcphs.hr, Hrvatski centar za poljoprivredu, hranu i selo, Zavod za zaštitu bilja, Gorice 68b, 10000 Zagreb
} 


\section{UVOD}

\section{INTRODUCTION}

Na biljkama domaćinima iz roda Quercus L. u svijetu je do sada registrirano ukupno 657 vrsta štitastih uši (Hemiptera: Coccomorpha). Na području Palearktičke regije u koju spada i Hrvatska, zabilježene su 153 vrste iz 13 različitih porodica i to kako slijedi: Asterolecaniidae, Beesoniidae, Coccidae, Diaspididae, Eriococcidae, Kermesidae, Kuwaniidae, Lecanodiaspididae, Pseudococcidae, Putoidae, Rhizoecidae, Steingeliidae i Xylococcidae (Ben- Dov i sur., 2015). Štitasta uš Kermes vermilio Planchon 1864 koja je 2014. registrirana kao novi član hrvatske entomofaune, pripada porodici Kermesidae. Porodica Kermesidae u svijetu obuhvaća 148, a u Palearktičkoj regiji 32 vrste. Na području Europe i Mediterana iz roda Kermes Boitard 1828 registrirano je 19 vrsta: Kermes bacciformis Leonardi 1908, K. bekiri Bodenheime 1953, K. biblicus (Bodenheimer 1926), K. bytinskii Sternlicht 1967, K. cordiformis Lindinger 1912, K. corticalis Nasonov 1908, K. echinatus 1953, K. gibbosus Signoret 1874, K. greeni Bodenheimer 1927, K. ilicis (Linnaeus 1758), K. muhlisi Bodenheimer 1941, K. nahalali Bodenheimer 1927, K. quercus (Linnaeus 1758), K. roboris (Fourcroy 1785), K. sadrii Bodenheimer 1953, K. safinazae Ozkok 1941, K. spatulatus Balachowsky 1953, K. vermilio Planchon 1864 i K. williamsi Sternlicht 1972 (Ben-Dov i sur., 2015).

Vrsta K. vermilio pronađena je samo na području Mediteranske regije. Do sada je registrirana u Alžiru, Francuskoj, Grčkoj, Italiji, Maroku, Portugalu, Španjolskoj, Turskoj (BenDov i sur., 2015) i Hrvatskoj. Leonardi (1920) spominje njenu prisutnost u Italiji, Španjolskoj, Francuskoj i Alžiru, još s početka dvadesetoga stoljeća.

U prošlosti, K. vermilio imala je značajnu gospodarsku važnost kao izvor crvenog bojila za tkaninu. U novije vrijeme za tu namjenu koristi se štitasta uš iz porodice Dactylopidae Dactylopius coccus Costa 1829. Dok s jedne strane vrsta K. vermilio može imati koristan učinak u gospodarstvu, $\mathrm{s}$ druge strane predstavlja gospodarski važnog štetnika, koji može u potpunosti uništiti biljku domaćina. Iako se dugo vremena ova vrsta javljala samo sporadično, 1987. u Italiji su registrirani napadi vrlo jakog intenziteta u urbanim sredinama, gdje je došlo do masovnog propadanja Q. ilex (Marotta i sur., 1999). Od tada do danas u Mediteranskoj regiji javljaju se napadi jakog intenziteta ove štitaste uši.

\section{MATERIJALI I METODE MATERIALS AND METHODS}

Temeljitim pregledom dostupne literature objedinjeni su podaci faunističkih istraživanja štitastih uši provedenih u Hrvatskoj. Korišteni su publicirani podaci dosadašnjih faunističkih istraživanja sljedećih autora: Balachowsky (1950), Kostarab \& Kozár (1988), Kovačević, (1961), Kozár (1983),

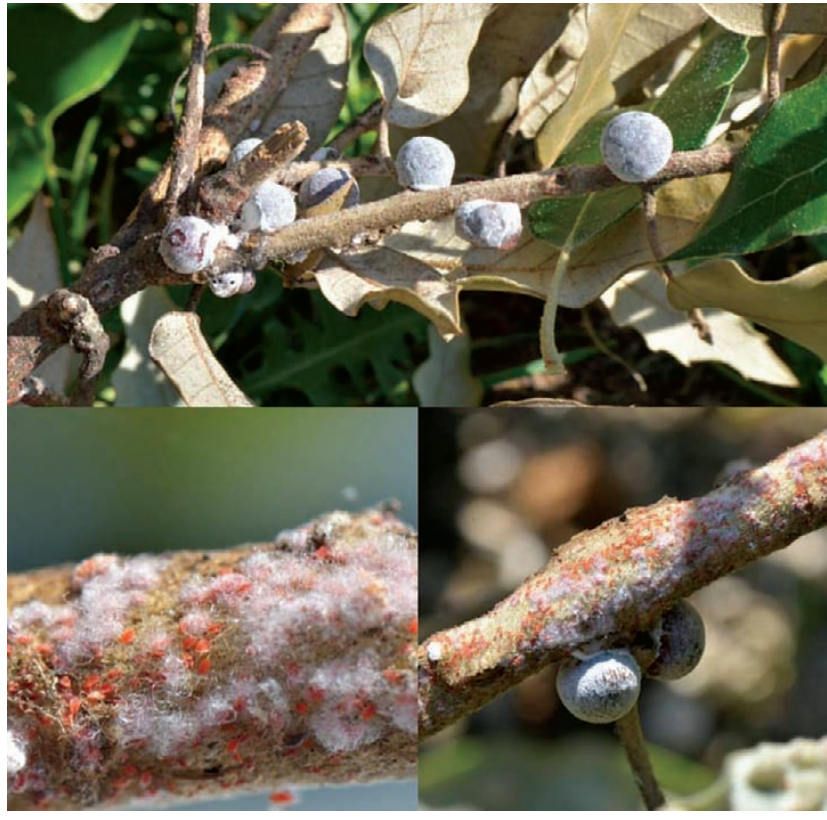

Slika 1. K. vermilio: gore odrasle ženke, dolje lijevo - ličinke, dolje desno - ličinke i odrasle ženke (snimila Tatjana Masten Milek)

Photo $1 \mathrm{~K}$. vermilio: above - adult female, down left - larvae, down right - larvae and adult female (photo Tatjana Masten Milek)

Langhoffer (1912, 1927, 1929), Lindinger (1912), Schmidt $(1955,1956,1973)$ i Žak-Ogaza (1967). Svakoj navedenoj vrsti dano je odgovarajuće ime u skladu s današnjom sistematikom (Ben Dov i sur., 2014).

Faunističko istraživanje štitastih uši započelo je 2005. godine i traje kontinuirano već 11 godina, na potencijalnim domaćinima na čitavome području Republike Hrvatske. Time su obuhvaćeni i domaćini iz roda Quercus (L.). Materijali i metode korišteni tijekom istraživanja bili su: vizualni pregledi, skupljanje uzoraka biljnog materijala, pohranjivanje i čuvanje uzoraka, obrada uzoraka pod binokularom, priprema mikroskopskih preparata i identifikacija. Uzorci su prikupljeni prema metodi Gill (1993). Obrada sakupljenih uzoraka napravljena je pod binokularom ZEISS Discovery V12 s pripadajućom digitalnom kamerom AxioCam ERc5s. Za obradu štitastih uši korištene su kemikalije: 70\% etilni alkohol, 10\% kalijev hidroksid, mliječna kiselina, acid fucksin i lignin pink, glacijalna octena kiselina i clove oil. Izrada trajnih mikroskopskih preparata obavljena je prema metodama Kosztarab \& Kozár (1988) i Gill (1993). Kod izrade trajnog mikoroskopskog preparata korištena je kemikalija canada balsam. Za identifikaciju štitastih uši do vrste korišteni su sljedeći ključevi: Balachowsky (1950), Borchsenius (1960), Gill (1993) i Pellizzari i sur. (2012), te svjetlosni mikroskop OLYMPUS BX 51 (objektivi s povećanjima 4x,10x, 20x, 40x i 100x, okulari s povećanjem 10x) s digitalnom kamerom OLYMPUS model DP25. Cjeloviti popis štitastih uši u Hrvatskoj sastavljen je objedinjavanjem faunističkih nalaza iz literature i faunističkih nalaza istraživanja. U popisu u uglatim zagra- 
dama prikazane su godine nalaza, a u okruglim zagradama ukupan broj faunističkih nalaza tj. učestalost pojavljivanja neke vrste.

\section{REZULTATI I RASPRAVA RESULTS AND DISCUSSION}

Rezultati rada sadrže prikaz objedinjenih literaturnih podataka faunističkih istraživanja štitastih uši na biljkama iz roda Quercus u Hrvatskoj (tablica 1.) i prikaz štitastih uši utvrđenih faunističkim istraživanjem (tablica 2.), s naglaskom na novozabilježenu vrstu za hrvatsku entomofaunu K. vermilio.

\section{Pregled literaturnih podataka faune štitastih uši}

Pretraživanjem literaturnih faunističkih podataka štitastih uši 20. stoljeća, sastavljen je popis od 15 vrsta iz 4 porodice. Podaci su prikazani u tablici 1.

Tablica 1. Popis zabilježenih štitastih uši na rodu Quercus L. na temelju literaturnog pregleda faunističkih istraživanja u Hrvatskoj (1900. - 1981.) Table 1. Incorporate list of scale insects on Quercus L. genera in Croatia, according to literature data (1900 - 1981)

\begin{tabular}{|c|c|c|c|c|}
\hline $\begin{array}{l}\text { PORODICA - Family } \\
\text { VRSTA - Species }\end{array}$ & $\begin{array}{l}\text { BILJKA DOMAĆIN } \\
\text { Host plant }\end{array}$ & $\begin{array}{l}\text { AUTOR I GODINA } \\
\text { OBJAVE - Author and } \\
\text { year of publication }\end{array}$ & $\begin{array}{l}\text { LOKALITET } \\
\text { Locality }\end{array}$ & $\begin{array}{l}\text { GODINA NALAZA } \\
\text { Year of finding }\end{array}$ \\
\hline \multicolumn{5}{|l|}{ Asterolecanidae } \\
\hline \multirow{3}{*}{ Asterodiaspis ilicicola (Targioni Tozzetti 1888) } & Quercus ilex L. & Schmidt, 1956 & Opatija & 1951. \\
\hline & Quercus ilex L. & Schmidt, 1956 & Rijeka & 1953. \\
\hline & Quercus ilex L. & Schmidt, 1973 & Opatija & 1965. \\
\hline \multirow{2}{*}{ Asterodiaspis variolosa (Ratzeburg 1870) } & Quercus robur L. & Lindinger, 1912 & Lošinj & 1912. \\
\hline & Quercus ilex L. & Schmidt, 1956 & Brioni & 1954. \\
\hline \multicolumn{5}{|l|}{ Coccidae } \\
\hline \multirow{5}{*}{ Coccus hesperidum Linnaeus 1758} & Quercus ilex L. & Schmidt, 1956 & Opatija & 1951. \\
\hline & Quercus ilex L. & Schmidt, 1956 & Opatija & 1953. \\
\hline & Quercus ilex $\mathrm{L}$. & Schmidt, 1973 & Opatija & 1960. \\
\hline & Quercus ilex L. & Schmidt, 1973 & Opatija & 1961. \\
\hline & Quercus ilex L. & Schmidt, 1973 & Opatija & 1962. \\
\hline \multirow{2}{*}{ Eulecanium tiliae (Linnaeus 1758) } & Quercus robur L. & Schmidt, 1956 & Šašinovac & 1947. \\
\hline & Quercus robur L. & Schmidt, 1956 & Zaprešić & 1947. \\
\hline Parthenolecanium rufulum (Cockerell 1903) & Quercus pubescens $\mathrm{L}$. & Kozar, 1983 & Lipica & 1981. \\
\hline Pulvinaria sericea (Fourcroy 1785) & Quercus pubescens $\mathrm{L}$. & Langhoffer, 1929 & Rab & 1929. \\
\hline \multicolumn{5}{|l|}{ Diaspididae } \\
\hline \multirow[t]{2}{*}{ Chionaspis salicis (Linnaeus 1758) } & $\begin{array}{l}\text { Quercus petraea } \\
\text { (Mattuschka) Liebl. }\end{array}$ & Schmidt, 1956 & Zagreb & 1940. \\
\hline & Quercus robur L. & Schmidt, 1956 & Lovas & 1946. \\
\hline Diaspidiotus ostreaformis (Curtis 1843) & Quercus L. sp. & Schmidt, 1956 & ne navodi & ne navodi \\
\hline \multirow{2}{*}{ Diaspidiotus zonatus (Frauenfeld 1868) } & Quercus robur $\mathrm{L}$. & Schmidt, 1956 & Lovas & 1946. \\
\hline & Quercus pubescens Willd. & Balachowsky, 1950 & Dalmacija & 1950. \\
\hline $\begin{array}{l}\text { Gonaspidiotus minimus (Leonardi in: Berlese } \\
\text { \& Leonardi 1896) }\end{array}$ & Quercus ilex L. & Lindinger, 1912 & Lošinj & 1912. \\
\hline Lepidosaphes beckii (Newman 1869) & Quercus L. sp. & Kovačević, 1961 & Hrvatska u području Jadrana & 1952. \\
\hline Lepidosaphes ulmi (Linnaeus 1758) & Quercus L. sp. & Schmidt, 1956 & Proširena u cijeloj Hrvatskoj & ne navodi \\
\hline \multirow{2}{*}{ Targionia vitis (Signoret 1869) } & Quercus L. sp. & Kovačević, 1961 & Primorje Dalmacija & 1952. \\
\hline & Quercus ilex $\mathrm{L}$. & Žak - Ogaza, 1967 & Rab & 1965. \\
\hline \multicolumn{5}{|l|}{ Kermesidae } \\
\hline \multirow{2}{*}{ Kermes roboris (Fourcroy 1785) } & Quercus robur $\mathrm{L}$. & Langhoffer, 1927 & Valpovo & 1925. \\
\hline & Quercus robur $\mathrm{L}$. & Schmidt, 1956 & Lovas & 1945. \\
\hline \multirow{6}{*}{ Kermes quercus (Linnaeus 1758) } & Quercus robur $\mathrm{L}$. & Langhoffer, 1927 & Bregi (Slavonija) & 1900. \\
\hline & Quercus robur $\mathrm{L}$. & Langhoffer, 1927 & Veliki Djol - Banova Jaruga & 1925. \\
\hline & Quercus robur L. & Langhoffer, 1929 & Koprivnički bregi & 1925. \\
\hline & Quercus robur L. & Schmidt, 1956 & Spačva & 1952. \\
\hline & Quercus robur $\mathrm{L}$. & Schmidt, 1956 & Mikanovci-Gajin vir & 1952. \\
\hline & Quercus robur $\mathrm{L}$. & Schmidt, 1956 & Šašinovac & 1955. \\
\hline
\end{tabular}


Tablica 2. Rezultati faunističkog istraživanja štitastih uši na domaćinima iz roda Quercus L. u razdoblju od 2005. do 2014. Table 2. Results of faunistic investigation of scale insects on host plants from genera Quercus L. in period from 2005 until 2014

\begin{tabular}{|c|c|c|c|}
\hline $\begin{array}{l}\text { PORODICA - Family } \\
\text { VRSTA - Species }\end{array}$ & $\begin{array}{l}\text { BILJKA DOMAĆIN } \\
\text { Host plant }\end{array}$ & $\begin{array}{l}\text { LOKALITET } \\
\text { Locality }\end{array}$ & $\begin{array}{l}\text { DATUM } \\
\text { Date }\end{array}$ \\
\hline \multicolumn{4}{|l|}{ Asterolecanidae } \\
\hline \multirow{13}{*}{ Asterodiaspis ilicicola (Targioni Tozzetti 1888) } & Quercus ilex $\mathrm{L}$. & Malinska Krk & 3.5.2006. \\
\hline & Quercus pubescens Willd. & Molunat & 24.7.2006. \\
\hline & Quercus pubescens Willd. & Dubrovnik & 24.7.2006. \\
\hline & Quercus ilex L. & Fažana & 13.12.2006. \\
\hline & Quercus coccifera L. & Moćići & 14.12.2006. \\
\hline & Quercus pubescens Willd. & Ćilipi & 14.12.2006. \\
\hline & Quercus ilex L. & Hrastovica Cres & 29.5.2007. \\
\hline & Quercus ilex L. & Molunat & 10.7.2008. \\
\hline & Quercus coccifera L. & Orebić & 23.9.2010. \\
\hline & Quercus coccifera L. & Korčula & 23.9.2010. \\
\hline & Quercus ilex L. & Korčula & 23.9.2010. \\
\hline & Quercus ilex L. & Opatija & 9.2 .2011 \\
\hline & Quercus ilex $\mathrm{L}$. & Rovinj & 19.05.2014. \\
\hline \multirow[t]{2}{*}{ Asterodiaspis quercicola (Bouche 1851) } & Quercus pubescens Willd. & Bijele Zemlje & 18.6.2008. \\
\hline & Quercus L. sp. & Našice & 1.6.2006. \\
\hline \multirow[t]{2}{*}{ Asterodiaspis variolosa (Ratzeburg 1870) } & Quercus roboris $\mathrm{L}$. & Vinkovci & 23.4.2007. \\
\hline & Quercus petraea L. & Zagreb & 2.5.2007. \\
\hline \multicolumn{4}{|l|}{ Coccidae } \\
\hline \multirow{5}{*}{ Parthenolecanium rufulum (Cockerell 1903) } & Quercus sp. Michx. & Velika Gorica (Pleso) & 24.6.2006. \\
\hline & Quercus robur L. & Velika Gorica (Pleso) & 27.8.2006. \\
\hline & Quercus roboris $\mathrm{L}$. & Samobor (Anindol) & 22.4.2007. \\
\hline & Quercus roboris $\mathrm{L}$. & Vinkovci & 23.4.2007. \\
\hline & Quercus cerris $\mathrm{L}$. & Klokočevik & 14.5.2009. \\
\hline \multicolumn{4}{|l|}{ Diaspididae } \\
\hline \multirow[t]{2}{*}{ Chionaspis etrusca Leonardi 1908} & Quercus pubescens Willd. & Makale & 4.9.2008. \\
\hline & Quercus ilex L. & Ugljan & 20.7.2009. \\
\hline \multirow{2}{*}{ Chionaspis lepineyi Balachowsky 1928} & Quercus ilex L. & Lopari Lošinj & 11.7.2014. \\
\hline & Quercus ilex L. & Merag Cres & 11.7.2014. \\
\hline Diaspidiotus alni (Marchal 1909) & Quercus pubescens Willd. & Bijele Zemlje & 11.11.2008. \\
\hline \multirow[t]{2}{*}{ Diaspidiotus bavaricus (Lindinger 1912) } & Quercus L. sp. & Belec & 27.9.2008. \\
\hline & Quercus ilex L. & Opatija & 9.2.2006. \\
\hline \multirow{3}{*}{ Gonaspidiotus minimus (Leonardi in: Berlese \& Leonardi 1896) } & Quercus borealis Michx. & Konavoske stijene & 24.7.2006. \\
\hline & Quercus pubescens Willd. & Ćilipi & 14.12.2006. \\
\hline & Quercus ilex L. & Ližnjan & 9.4.2007. \\
\hline \multirow{3}{*}{ Targionia vitis (Signoret 1869) } & Quercus pubescens Willd. & Jadrija & 1.5.2007. \\
\hline & Quercus pubescens Willd. & Šibenik & 24.5.2008. \\
\hline & Quercus ilex L. & Merag Cres & 11.7.2014. \\
\hline \multicolumn{4}{|l|}{ Kermesidae } \\
\hline Kermes roboris (Fourcroy 1785) & Quercus robur $\mathrm{L}$. & Zagreb & 5.8.2013. \\
\hline Kermes vermilio Planchon $1864^{*}$ & Quercus ilex L. & Poreč & 22.8.2014. \\
\hline
\end{tabular}

Ukupno: 4 porodice i 12 vrsta štitastih uši - Total: 4 families and 12 species of scale insects

*Novozabilježena vrsta štitaste uši u Hrvatskoj - *Newly recorded species of scale insects in Croatia

Istraživanje faune štitastih uši u razdoblju od 2005. do 2014. - Faunistic investigation of scale insects in period from 2005 until 2014

Istraživanje faune štitastih uši u razdoblju od 2005. do 2014. rezultiralo je popisom od 12 vrsta iz 4 porodice. Podaci su prikazani u tablici 2.

\section{Popis štitastih uši Hrvatske - Check list of scale insects of Croatia}

Popis štitastih uši Hrvatske obuhvaća sve fanustičke podatke literature i podatke istraživanja. Rezultati su prikazani u tablici 3. 
Tablica 3. Popis štitastih uši na domaćinima iz roda Quercus L. u Hrvatskoj u razdoblju 1900.- 2014. (u uglatoj zagradi navedene su godine pojavljivanja, a u okrugloj učestalost pojave vrste u literaturnim podacima i faunističkim istraživanjima)

Table 3. Check list of scale insects on host plants from genera Quercus L. in Croatia in period 1900-2014 (brackets contain years of appearance, parenthesis contain number of appearance in literature data and faunistic investigation)

\begin{tabular}{|c|c|c|}
\hline \multicolumn{3}{|c|}{ I Porodica- Family: Asterolecanidae } \\
\hline \multirow{3}{*}{ Rod - Genus } & \multirow{3}{*}{ Asterodiaspis Signoret 1877} & $\begin{array}{l}\text { 1. Asterodiaspis ilicicola (Targioni Tozzetti 1888) [1951; 1953; 1955; 2006; 2007; 2008; 2010; } \\
2011 ; 2014] \text { (16) }\end{array}$ \\
\hline & & 2. Asterodiaspis quercicola (Bouche 1851) [2008] (1) \\
\hline & & 3. Asterodiaspis variolosa (Ratzeburg 1870) [1912; 1954; 2006; 2007] (4) \\
\hline \multicolumn{3}{|c|}{ II Porodica- Family: Coccidae } \\
\hline Rod-Genus & Coocus Linnaeus 1758 & 4. Coccus hesperidum Linnaeus 1758 [1951; 1953; 1960; 1961; 1962] (5) \\
\hline Rod-Genus & Eulecanium Cockerell 1893 & 5. Eulecanium tiliae (Linnaeus 1758) [1947] (2) \\
\hline Rod-Genus & Parthenolecanium Šulc 1908 & 6. Parthenolecanium rufulum Cockerell 1903 [1981; 2006; 2007, 2009] (11) \\
\hline Rod-Genus & Pulvinaria Targioni Tozzetti 1866 & 7. Pulvinaria sericea (Fourcroy 1785) [1929] (1) \\
\hline \multicolumn{3}{|c|}{ III Porodica- Family: Diaspididae } \\
\hline \multirow{3}{*}{ Rod - Genus } & \multirow{3}{*}{ Chionaspis Signoret 1869} & 8. Chionaspis etrusca Leonardi 1908 [2008; 2009] (2) \\
\hline & & 9. Chionaspis lepineyi Balachowsky 1928 [2014 x2] (2) \\
\hline & & 10. Chionaspis salicis (Linnaeus 1758) [1940; 1946] (2) \\
\hline \multirow{4}{*}{ Rod - Genus } & \multirow{4}{*}{ Diaspidiotus Berlese \& Leonardi 1896} & 11. Diaspidiotus alni (Marchal 1909) [2008] (1) \\
\hline & & 12. Diaspidiotus bavaricus (Lindinger 1912) [2008] (1) \\
\hline & & $\begin{array}{l}\text { 13. Diaspidiotus ostreaeformis (Curtis 1843) [autor ne navodi godinu, ali spominje vrstu da } \\
\text { obitava na hrastu] (1) }\end{array}$ \\
\hline & & 14. Diaspidiotus zonatus (Frauenfeld 1868) [1946; 1950] (2) \\
\hline \multirow[t]{2}{*}{ Rod - Genus } & \multirow[t]{2}{*}{ Gonaspidiotus MacGillivray 1921} & 15. Gonaspidiotus minimus (Leonardi in: Berlese \& Leonardi 1896) [1912; 2006; 2007] (5) \\
\hline & & 16. Lepidosaphes beckii (Newman 1869) [2008] (1) \\
\hline Rod-Genus & Lepidosaphes Shimer 1868 & $\begin{array}{l}\text { 17. Lepidosaphes ulmi (Linnaeus 1758) [autor ne navodi godinu, ali spominje vrstu da obitava } \\
\text { na hrastu] (1) }\end{array}$ \\
\hline Rod & Targionia Signoret 1869 & 18. Targionia vitis (Signoret 1876) [1952; 1965; 2007; 2014] (5) \\
\hline \multicolumn{3}{|c|}{ IV Porodica-Family: Kermesidae } \\
\hline \multirow{3}{*}{ Rod-Genus } & \multirow{3}{*}{ Kermes Boitard 1828} & 19. Kermes quercus (Linnaeus 1758) [1900; 1925; 1952; 1955] (6) \\
\hline & & 20. Kermes roboris (Fourcroy 1785) [1925; 1945; 2013] (3) \\
\hline & & 21. Kermes vermilio Planchon 1864 [2014] (1) \\
\hline
\end{tabular}

Ukupno: 4 porodice, 11 rodova i 21 vrsta štitaste uši na hrastovima u Hrvatskoj Total: 4 families, 11 genera and 21 species of scale insects on oaks in Croatia

Na području Palearktičke regije u koju spada i Hrvatska, zabilježene su 153 vrste iz 13 različitih porodica na biljkama domaćinima iz roda Quercus L., dok je u Hrvatskoj registrirana 21 vrsta iz četiri porodice. Potrebno je istaknuti da u Hrvatskoj nisu postojala sustavna faunistička istraživanja štitastih uši, s iznimkom razdoblja u kojemu je djelovala prof. dr. sc. Lea Schmidt (Schmidt, 1955, 1956. i 1973) i razdoblja od 2005. od kada se kontinuirano provode faunistička istraživanja koja traju i danas (Masten Milek, 2007, Masten Milek i sur., 2007). Iz grafikona 1. vidljivo je da se vrsta A. ilicicola najčešće pojavljivala tijekom faunističkih istraživanja, a potom slijedi $P$. rufulum. Grafikon 2. ukazuje nam da smo na biljkama domaćinima iz roda Quercus u najvećem postotku bilježili vrste iz porodice Diaspididae, zatim iz porodice Asterolecanidae, pa Coccidae i na kraju Kermesidae.

\section{OPIS NOVOZABILJEŽENE VRSTE DESCRIPTION OF NEWLY RECORDED SPECIES}

Odrasla postreproduktivna ženka K. vermilio kuglastog je oblika, tamno crvene ili smeđe boje, pokrivena tankim slojem bijelog ili svjetlo sivog voštanog praha (slika 1.). Duljina tijela kreće se oko $5 \mathrm{~mm}$, širina oko $4,7 \mathrm{~mm}$, a visina oko 4,6 $\mathrm{mm}$. Zbog jako zadebljane (sklerotizirane) kutikule, jedinka je u toj fazi razvoja neprikladna za pouzdanu dijagnostičku analizu na temelju mikroskopskih morfoloških karakteristika. Odrasle ženke K. vermilio u usporedbi s većinom drugih vrsta roda Kermes, nemaju noge. Za razliku od većine vrsta štitastih uši, čija se dijagnostika obavlja isključivo na temelju mikroskopskih morfoloških karakteristika teneralne ženke, kod vrsta iz porodice Kermesidae, dijagnosticiranje 


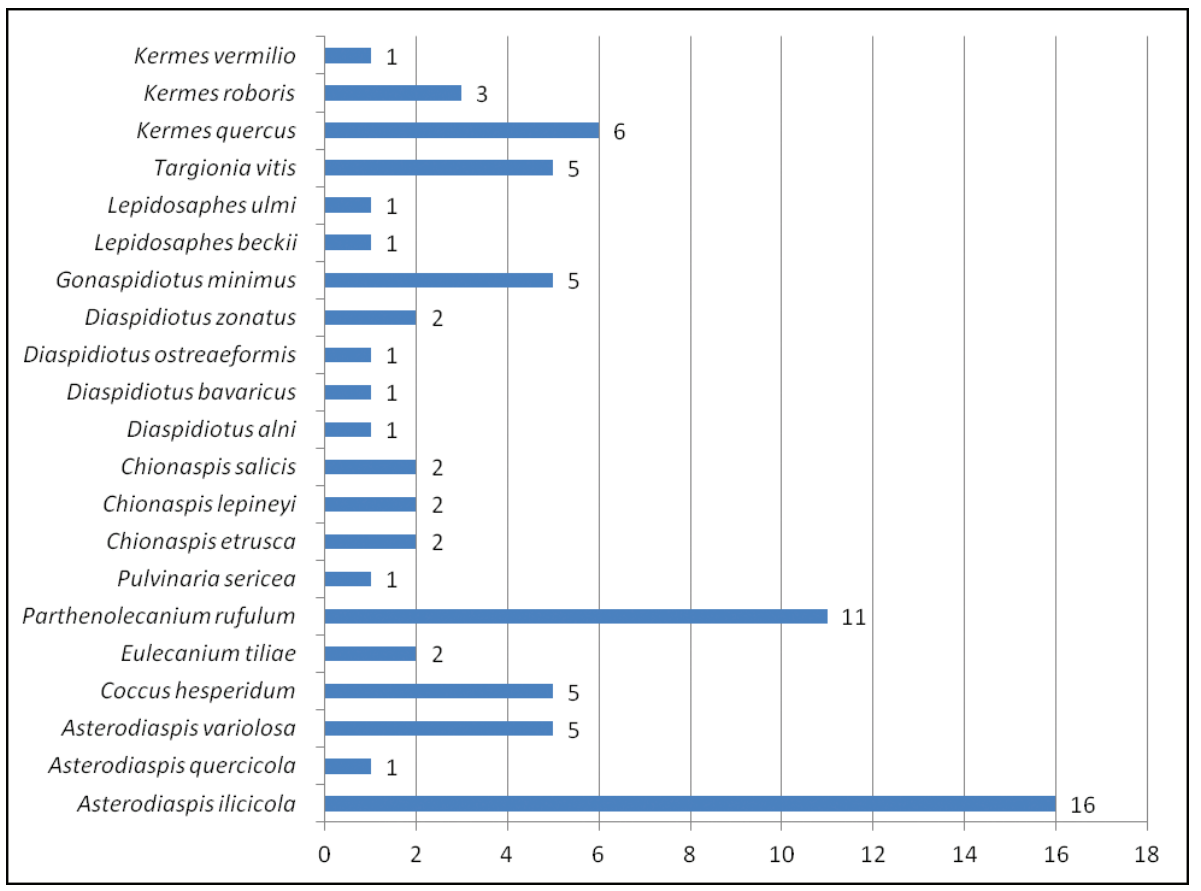

Grafikon 1. Broj pojavljivanja štitastih uši na domaćinima iz roda Quercus L. u Hrvatskoj u razdoblju 1900. - 2014. Graph 1 Number of scale insect appearing on host plants from genera Quercus L. in Croatia in period 1900-2014

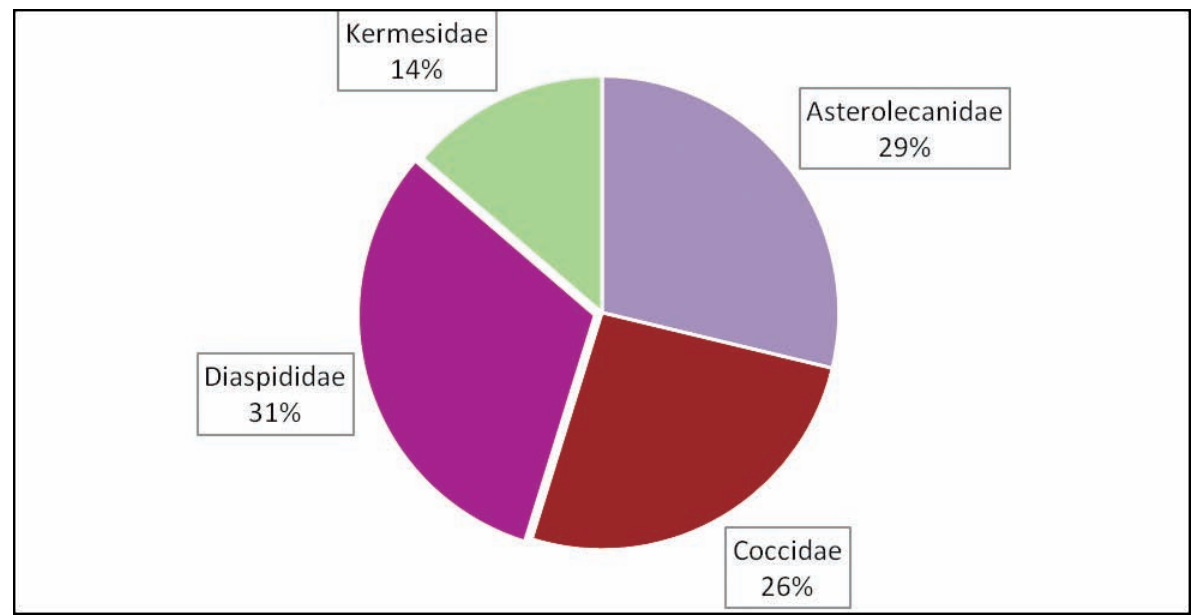

Grafikon 2. Postotak pojavljivanja štitastih uši po porodicama na domaćinima iz roda Quercus L.

Graph 2 The percentage of appearing of scale insects in families on host plants from genera Quercus $\mathrm{L}$.

se provodi i na temelju morfoloških ključeva za ličinke ženki $\left(\mathrm{L}_{1}, \mathrm{~L}_{2}, \mathrm{~L}_{3}\right)$ i mužjaka $\left(\mathrm{L}_{1}, \mathrm{~L}_{2}\right)$. Tijelo ličinke ženke prvog stadija izduženog je, ovalnog oblika, spljošteno, narančasto crvene boje sa žutim nogama. Na početku su prekrivene bijelim praškastim voskom, a nakon toga bijelim voštanim vlaknima (slika 1.). Kod jedinki koje idu na prezimljenje, na leđnoj strani (dorzumu) prisutni su pravilno raspoređeni voštani čuperci. U odnosu na druge mediteranske i europske vrste iz roda Kermes, ličinku ženke prvog stadija K. vermilio, relativno je lako razlikovati po prisutnosti čunjastih rubnih seta, bodljastog oblika (slika 2.). Ličinka ženke prvog stadija vrste $K$. echinatus, također ima slične rubne sete, no kod ove vrste one su dulje i lagano zakrivljene.
Ličinka ženke drugog stadija K. vermilio ovalnog je oblika, crvene boje s pravilno raspoređenim voštanim čupercima na leđnoj strani, s voštanim nitima na rubovima. Tijelo ličinke ženke trećeg stadija je široko ovalnog ili polukuglastog oblika, crvene ili smeđe boje. Leđna strana pokrivena je staklastim voskom, s pravilno raspoređenim čunjastim čupercima voska koji strše (Pellizzari i sur., 2012). K. vermilio ima 1 generaciju godišnje. Ličinke se javljaju krajem svibnja i početkom lipnja (Leonardi, 1920).

Vrsta K. vermilio prvi je puta uočena u parku u Poreču (N $45^{\circ} 13^{\prime}$ E $13^{\circ} 37^{\prime}$ ) dana 22.8.2014. Tom prilikom uočene su brojne jedinke ovog štetnika na granama $Q$. ilex. Istovremeno prisutne su bile i odrasle jedinke i ličinke različitih 


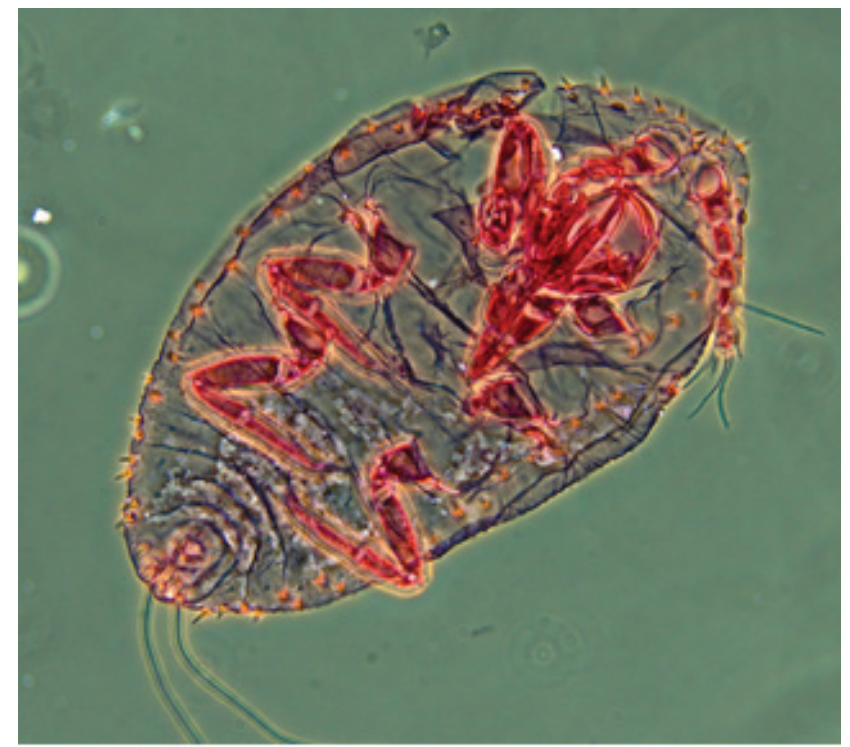

Slika 2. Mikroskopski preparat ličinke (L1) K. vermilio (povećanje 20x) (snimila Tatjana Masten Milek)

Photo 2 Slide of female larvae (L1) of K. vermilio (magnification 20x) (photo Tatjana Masten Milek)

razvojnih stadija, što dodatno otežava suzbijanje. Stabla hrasta crnike sušila su se i kod nekih je došlo do potpunog odumiranja (slika 3.). To je prvi nalaz ovog štetnika za Hrvatsku. Uslijed pojačanog intenziteta međunarodne trgovine biljnim sadnim materijalom, logično je da se javljaju brojne nove vrste štetnih organizama kako u drugim zemljama, tako i u Hrvatskoj. Upravo zbog navedene činjenice, kao i zbog recentnih promijenjenih klimatskih uvjeta u našoj zemlji (Kaučić, 2016), koji pogoduju većini štetnih organizama, potreban je kontinuirani monitoring, posebice u domeni karantenskih štetnih organizama, koji može spriječiti ili usporiti širenje novih vrsta u Hrvatskoj. Osim toga, svakako je potrebno istražiti i učinkovite načine suzbijanja ovog štetnika.

\section{ZAKLJUČAK CONCLUSION}

Prema literaturnim izvorima u Hrvatskoj registrirano je 15 vrsta štitastih uši na hrastu. Istraživanjima je utvrđeno 12 vrsta štitastih uši, od kojih je u odnosu na vrste iz literaturnih podataka registrirano šest novih. U ovom trenutku popis štitastih uši na hrastu obuhvaća 21 vrstu iz četiri porodice kako slijedi: porodica Asterolecanidae: Asterodiaspis ilicicola (Targioni Tozzetti 1888); A. quercicola (Bouche 1851); A. variolosa (Ratzeburg 1870); porodica Coccidae: Coccus hesperidum Linnaeus 1758; Eulecanium tiliae (Linnaeus 1758); Parthenolecanium rufulum Cockerell 1903; Pulvinaria sericea (Fourcroy 1785); porodica Diaspididae: Chionaspis etrusca Leonardi 1908; C. lepineyi Balachowsky 1928; C. salicis (Linnaeus 1758); Diaspidiotus alni (Marchal 1909); D. bavaricus (Lindinger 1912); D. ostreaeformis (Curtis 1843); D. zonatus (Frauenfeld 1868); Gonaspidiotus minimus (Leonardi in: Berlese \& Leonardi 1896), Lepidosaphes beckii (Newman 1869); L. ulmi (Linnaeus 1758); Targionia vitis (Signoret 1876) i porodica Kermesidae: Kermes quercus (Linnaeus 1758); K. roboris (Fourcroy 1785) i K. vermilio Planchon 1864.

U srpnju 2014. godine, zamijećena je masovna pojava štitaste uši K. vermilio i znakovi napada na hrastu crnici u Poreču. Ona je novi član hrvatske entomofaune. Zbog velikih šteta koje može pričinjati $K$. vermilio i činjenice da se ova
Slika 3. Jaki napad $K$. vermilio na Q. ilex (snimila Tatjana Masten Milek)

Photo 3 Severe infestation of $Q$. ilex caused by K. vermilio (photo Tatjana Masten Milek)

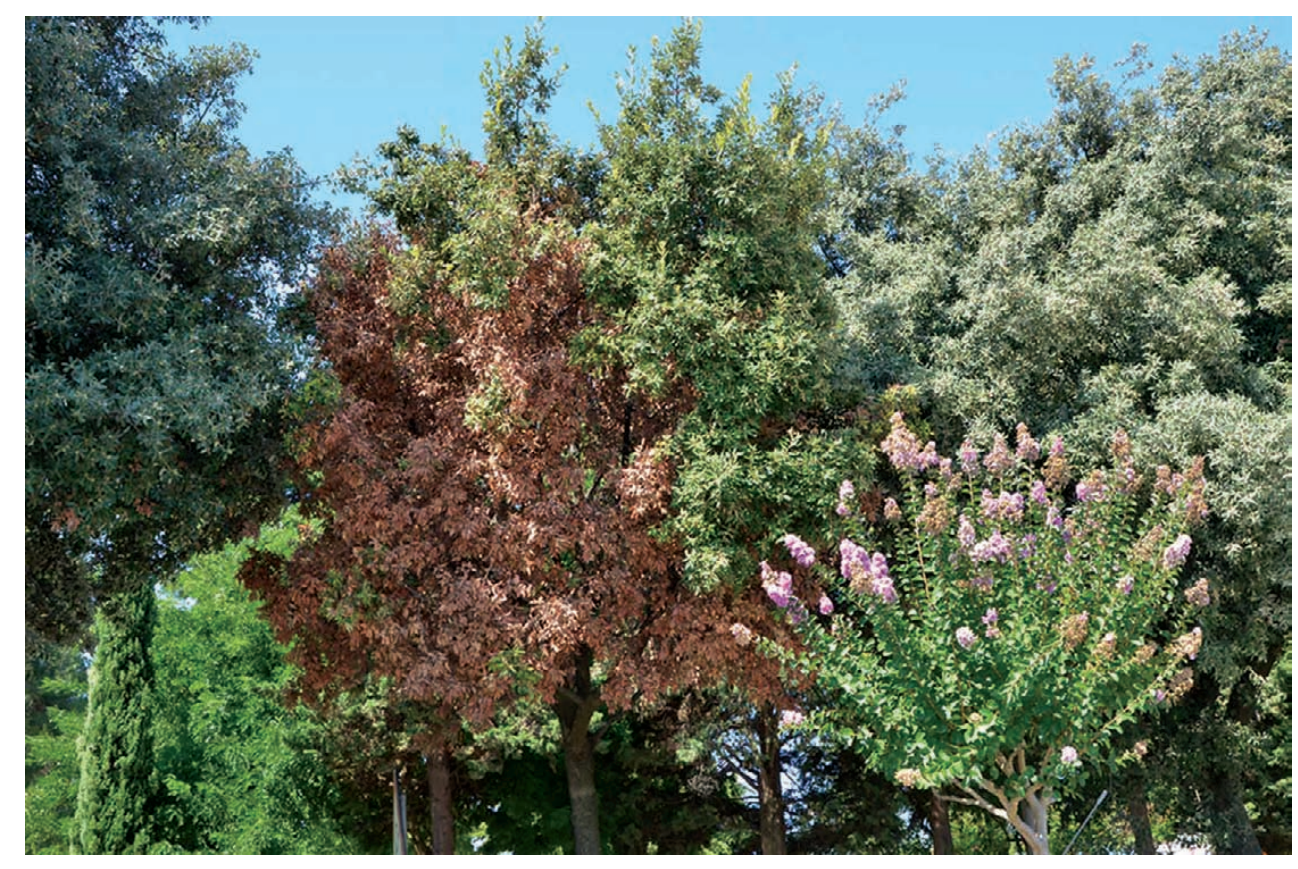


vrsta udomaćila u drugim zemljama Mediterana, potrebno je nastaviti monitoring. Svrha monitoringa je sprječavanje ili usporavanje širenja ovog štetnika u Hrvatskoj, s ciljem sprječavanja ili smanjenja šteta koje K.vermilio može pričinjati.

\section{LITERATURA} REFERENCES

- Balachowsky, A. S., 1950: Les cochenilles de France, d'Europe, du nord de l'Afrique et du bassin Méditerranéen, V. Monographie des Coccoidea, classification - Diaspidinae (deuxiene partie) Aspidiotini, Act. Sci. Indust. 1087: 398-557

- Ben-Dov, Y., Miller, D.R. \& Gibson, G.A.P., 2014: ScaleNet: a database of the scale insects of the world. Available from http:// www.sel.barc.usda.gov/scalenet/scalenet.htm

- Borchsenius, N. S., 1960: Fauna of USSR, Homoptera, Kermococcidae, Asterolecaniidae, Lecanidodiaspididae, Aclerdidae, Akademiia nauk SSSR, Zoologicheskii institut (Series), 282 pp., Leningrad

- Gill, R. J., 1993: The Scale Insects of California, Part II: The Minor Families (Homoptera: Coccoidea) Margarodidae, Orthezidae, Kerriidae, Asterolecanidae, Lecanodiaspididae, Cerococcidae, Aclerididae, Kermesidae, Dactylopiidae, Eriococcidae and Phoenicoccidae, California Department of Food and Agriculture, 241 pp., Sacramento

- Kaučić, D., 2016: Ekstremi osnovnih meteoroloških elemenata posljednjih deset godina i mogući utjecaj na pojavu i širenje biljnih bolesti i štetnika. Glasilo biljne zaštite $1 / 2$ dodatak: 15

- Kosztarab, M., Kozár, F., 1988: Scale Insects of Central Europe, Series Entomologica, Vol. 41, Akademiai Kiado, 456 pp., Budapest

- Kozár, F., 1983: New and little known scale insect species from Yugoslavia (Homoptera: Coccoidea), Acta Zool. Acad. Sci. Hungaricae, 29: 139-149
- Kovačević, Ž., 1961: Primjenjena entomologija, II knjiga, Poljoprivredni štetnici, Poljoprivredni nakladni zavod, 99-139., Zagreb

- Langhoffer, A., 1927: Štetočinje hrasta osim gubara, Glasnik za šumske pokuse, 2, 150-185., Zagreb

- Langhoffer, A., 1929: Les insectes nuisibles aux arbres fruitiers principalement en Croatie, Slavonie et Dalmatie, XIV-eme Congres International d'agriculture, Bucarest.

- Lindinger, L., 1912: Die Schildläuse (Coccidae) Europas, Nordafrikas und Vorder-Asiens, einschliesslich der Azoren, der Kanaren und Madeiras, 388 pp., Stuttgart

- Marotta, S., Ripullone, F. \& Tranfaglia, A., 1999: Osservazioni bio-etologiche su Kermes vermilio (Planchon) (Homoptera Coccoidea Kermesidae) dannoso ai lecci in Basilicata. Phytophaga, 9, 63-83.

- Masten Milek, T., 2007: Fauna štitastih uši (Insecta: Coccoidea) u Republici Hrvatskoj, Poljoprivredni fakultet u Osijeku, doktorska disertacija / Fauna of scale insects (Insecta: Coccoidea) in the Republic of Croatia, Faculty of Agricuture in Osijek, Doctoral Thesis: $242 \mathrm{pp}$.

- Masten Milek, T., Šimala, M., 2007: List of the scale insects (Hemiptera, Coccoidea) of Croatia, International Symposium on Scale Insect Studies, Program and Abstracts, 24th-27th September 2007, 58., Oeiras, Portugal

- Pellizzari, G., Porcelli, F., Convertini, S., Marotta, S., 2012: Description of nymphal instars and adult female of Kermes vermilio Planchon (Hemiptera, Coccoidea, Kermesidae), with a synopsis of the European and Mediterranean species, Zootaxa 3336, Magnolia Press: 36 - 50

- Schmidt, L., 1955: Prilog fauni štitastih ušiju Hrvatske s obzirom na njihove biljke hraniteljice, Biološki glasnik, 8: 77-88

- Schmidt, L., 1956: Štitaste uši Hrvatske, Zaštita bilja, 36: 5-11

- Schmidt, L., 1973: Štitaste i lisne uši na ukrasnom bilju Opatije i Rijeke, Poljoprivredna znanstvena smotra, 30 (40): 439-453

- Žak-Ogaza, B., 1967: Materials to the knoledge of the scale insects fauna of Yugoslavia (Homoptera, Coccoidea), Acta Zool. Cracov., 9: 211-218

\section{Summary}

Check-list of scale insects (Hemiptera: Coccomorpha) on host plants of genus Quercus L. comprises all available literature data on faunistic research of scale insects in Croatia, as well as data from the research conducted from 2005 to 2014. Published data on former faunistic research from the following authors have been used: Balachowsky (1950), Kovačević (1961), Kozár (1983), Langhoffer (1927, 1929), Lindinger (1912), Schmidt $(1956,1973)$ and Žak-Ogaza (1967). Each listed species was matched with a corresponding name, according to current systematics (Ben Dov et al., 2014). Following materials and methods were used in conducted research: visual inspections, collecting of plant material, storing and preservation of samples, analysis of samples under stereomicroscope, preparation of microscopic slides and identification of species. Samples were collected according to the method by Gill (1993). Analysis of collected samples was done under ZEISS Discovery V12 stereomicroscope with appurtenant AxioCam ERc5s digital camera. 70\% ethyl alcohol, potassium hydroxide, lactic acid, fuchsine acid, lignin pink, acetic acid and clove oil were used in processing of scale insects' samples. Permanent microscopic slides (photo 2) were prepared using clove oil, accordingly to Kosztarab \& Kozár, 1988 and Gill, 1993. Identification of scale insect species was conducted using identification keys by Balachowsky, 1950, Borchsenius, 1960, Gill, 1993 and Pellizzari et al., 2012, compound microscope OLYMPUS BX 51 (with 4x, 10x, 20x, 40x and 100x magnification lens and 10x magnification ocular) and 
OLYMPUS DP25 digital camera. Based on literature data, 15 species of scale insects have been registered on oak trees (table 1). Faunistic investigation of scale insects in period from 2005 to 2014 established 12 species of scale insects. When compared to literature data, 6 new species have been registered (table 2). Currently, the check-list of scale insects on oak trees in Croatia comprises 21 species belonging to 4 families: family Asterolecanidae: Asterodiaspis ilicicola (Targioni Tozzetti 1888), A. quercicola (Bouche 1851), A. variolosa (Ratzeburg 1870), family Coccidae: Coccus hesperidum Linnaeus 1758, Eulecanium tiliae (Linnaeus 1758), Parthenolecanium rufulum Cockerell 1903, Pulvinaria sericea (Fourcroy 1785), family Diaspididae: Chionaspis etrusca Leonardi 1908, C. lepineyi Balachowsky 1928, C. salicis (Linnaeus 1758), Diaspidiotus alni (Marchal 1909), D. bavaricus (Lindinger 1912), D. ostreaeformis (Curtis 1843), D. zonatus (Frauenfeld 1868), Gonaspidiotus minimus (Leonardi in: Berlese \& Leonardi 1896), Lepidosaphes beckii (Newman 1869), L. ulmi (Linnaeus 1758), Targionia vitis (Signoret 1876) and family Kermesidae: Kermes quercus (Linnaeus 1758), K. roboris (Fourcroy 1785) and K. vermilio Planchon 1864 (table 3). A. ilicicola had the highest number of appearing, followed by P. rufulum (graph 1). On host species from the genus Quercus, species from the family Diaspidide were dominant, followed by Asterolecanidae, Coccidae and Kermesidae (graph 2). In July 2014 mass occurrence of scale insect $K$. vermilio and symptoms of its infestation were registered on evergreen oak (Quercus ilex L.) in the town of Poreč (photo 2). Visual inspections were conducted and samples were collected. Diagnostic analysis based on morphological characteristics was carried out and it resulted in identification of scale insect K. vermilio (photo 1 ). K. vermilio is a new member of Croatian entomofauna, whose host plants are evergreen species belonging to the genus Quercus, primarily evergreen oak.

KEY WORDS: Croatia, first finding, kermes berry, Kermes vermilio, oak, scale insects 